\title{
ACTAS DEL II CONGRESO INTERNACIONAL DE SEMIÓTICA: «LO TEATRAL Y LO COTIDIANO»
}

\author{
Jesús G. Maestro \\ Universidad de Oviedo
}

A lo largo de los últimos años, a través de congresos diversos, la Asociación Española de Semiótica ha contribuido poderosamente a demostrar que el estudio intelectual de la literatura habrá de ser racional si pretende ser conocimiento. Indudablemente, esta postura científica de abordar intelectualmente el problema del arte, y en particular, del arte literario, procurando a la vez un estudio literario y sistemático del mismo, en gran medida supone la resolución de problemas tan duraderos como lo han sido la clasificación de las Ciencias, la Filosofia de la Historia y, sin duda, la Teoría del Conocimiento.

Efectivamente, las más actuales teorías de la literatura no constituyen sino una ficción explicativa que, bajo la apreciación de diferentes modelos teóricos de mayor o menor complejidad objetiva, nos posibilitan un «conocimiento organizado" de la realidad literaria. Así pues, la investigación literaria queda por fin al margen de intuiciones emocionales o personales apreciaciones de complejo subjetivismo, a la vez que comienza a entenderse como una tradición crítica suprapersonal. La Semiología Crítica, crecida a partir del formalismo ruso, la semiótica filosófica y la lingüistica estructural, es hoy un medio, no un fin en sí mismo. Se ha conseguido, en suma, que no penetren en el estudio de la literatura elementos extraños a ella.

Hace ya casi tres años que tuvo lugar en Oviedo la celebración del II Congreso Internacional de Semiótica bajo el tema de «Lo teatral y lo co- 
tidiano»'. En las actas del encuentro se han recogido las conferencias plenarias de María del Carmen Bobes, Herman Parret y Marco di Marinis, además de la sesión experimental a cargo de Jenaro Taléns, junto a las ochenta y seis comunicaciones presentadas al mencionado congreso en noviembre de 1986.

María del Carmen Bobes Naves, bajo el título de «Semiología del teatro: los signos de la representación", ofreció una conferencia plenaria en la que puso de relieve la doble dimensión del teatro: el texto dramático y la representación o puesta en escena de ese diálogo.

Tradicionalmente, la crítica literaria, al aproximarse al estudio del arte dramático, limitaba sus investigaciones al texto escrito, olvidándose por entero de todo lo referente a su representación y puesta en escena, a lo que consideraba como algo ajeno a la crítica misma. En el texto dramático hay un elemento específico, que diferencia el teatro de otros géneros: el diálogo, forma impuesta por la virtualidad de la representación.

El texto dramático, destinado a la representación, presenta dos tipos de lenguaje: el del diálogo (o texto principal) y el de las acotaciones (o texto secundario). El texto principal es eminentemente de carácter literario, mientras que el texto secundario es de carácter funcional. $Y$ en la representación desaparece como lenguaje, al ser sustituido por signos de sistemas semióticos muy diversos.

En suma, el objeto de la semiología no es sino el estudio de todos los sistemas de signos que pueden dar sentido a una obra. Lógicamente, su campo de investigación no debe limitarse a los signos lingüísticos, o a aquellos otros signos que únicamente aparecen en la escena. Como ha escrito Maria del Carmen Bobes, «la obra de teatro es para la semiología un conjunto de signos actualizados en simultaneidad en escena». Explicar el teatro exige, además del estudio del texto dramático, el estudio de su puesta en escena. Y esta es la última pretensión de la semiología en este ámbito: estudiar el fenómeno teatral en estas dos dimensiones. El semiólogo, en suma, se propone analizar el teatro como un conjunto de signos diversos, que buscan sentido coherente en cada representación.

' Existe una colección de cinco artículos periodísticos publicados en el diario La Nueva España, de Oviedo, en los que se recoge la información diaria que, a propósito de las comunicaciones y ponencias más representativas pronunciadas en el congreso, se desarrolló durante los días 13, 14 y 15 de noviembre de 1986. Vid. Maestro, J. G., «El jueves, inicio en Oviedo del II Simposio Internacional de Semiótica» ( 9 de noviembre); «Semiólogos de toda Europa, en el Simposio que hoy se inaugura en Oviedo" (13 de noviembre); «Numerosa asistencia de público al II Simposio de Semiótica. Carmen Bobes y Herman Parret hablaron ayer del teatro y de lo cotidiano" (14 de noviembre); "Jenaro Taléns: La televisión habla de una realidad que ella construye previamente" ( 15 de noviembre), y "Josefina Albert: La obra de Lorca es un magnifico monumento de la violencia» (16 de noviembre), La Nueva España, Oviedo, 1986. 
En «Les temporalités du quotidien», el profesor de la Universidad de Bruselas, Herman Parret, se manifesta como un semiólogo un tanto heterodoxo - según propias palabras- al asegurar que la semiótica de lo cotidiano constituye una provocación hacia los otros métodos de investigación. H. Parret demuestra en "Les temporalités...» una aplicación de la teoría semiótica consistente en buscar nuevas facetas y proposiciones en este campo de investigación, y, muy específicamente, en aquellos temas relacionados con la cotidianeidad.

Pensamos que aquí reside la aportación más singular y decisiva: tras la lectura de las Actas de este II Congreso de AES se comprueba que hasta hace poco la semiótica se había venido ocupando - casi exclusivamentedel estudio de los textos literarios lingüísticos, pero, precisamente, en nuestra actualidad más inmediata, certificamos que sus perspectivas de estudio van desde la arquitectura hasta lo cotidiano...

Según Herman Parret, la semiótica de lo cotidiano constituye una provocación hacia los otros métodos de investigación. Para el profesor de la Universidad de Bruselas lo teatral se opone en cierta medida a lo cotidiano, pues el teatro no hay que verlo como una asimilación de la vida cotidiana, sino que, por el contrario, depende de unas formas especificas, de unos estereotipos concretos, que hacen que el teatro se distancie abiertamente de la vida cotidiana. Desde este punto de vista, para algunos teóricos resultará fácil admitir que la semiótica de lo cotidiano constituye, en efecto, una "provocación» hacia otros métodos explicativos.

Por su parte, y también a propósito de lo cotidiano, G. Imbert, al hablar de "La ciudad como recorrido", convierte a la ciudad en un objeto semiótico en el que se reconoce una especialización privilegiada dentro del ámbito de lo cotidiano, dada su doble condición de espacio social y espacio vivencial. De este modo, la espacialidad que entraña la cotidianeidad urbana le lleva a considerar la ciudad como objeto semiótico desde tres ángulos diferentes: la ciudad como Actante, como Topos, y como recorrido del Sujeto en el espacio de realización. En suma, la ciudad queda configurada como «el lugar del aparecer y del parecer, lugar de la teatralidad cotidiana ${ }^{3}$. Así,

2 Desde la celebración del II Congreso de AES hasta nuestros dias, María del Carmen Bobes Naves ha proseguido sus investigaciones sobre el teatro con las dos obras siguientes: Semiología de la obra dramática, Madrid, Taurus, 1987, y Estudios de semiología del teatro. Valladolid, Aceña, 1988. A propósito de este último libro, puede verse la siguiente recensión: Maestro, J. G., "La Semiología y el teatro», La Nueva España, Oviedo, 13 de marzo de 1988.

"Imbert, G., "La ciudad como recorrido (aproximación figurativa a la realidad)", Actas del II Congreso Internacional de AES, Universidad de Oviedo, 1988, pp. 239-252, p. cit. 243. 
como ha escrito P. Sansot, la ciudad no es más que la serie de sus manifestaciones:

La definición de J. Baudrillard, según la cual la cotidianeidad es la diferencia en la repetición, nos ayuda a comprender el sentido último de «Lo cotidiano como clave lectoral de El otoño del patriarca», de Ángel Díaz Arenas. En su comunicación, este estudioso español que imparte docencia en Munich, pone en relación diversos elementos que aparecen diasporados en la sintaxis discursiva de la novela de Gabriel G. Márquez, con objeto de explicar tales signos o señales como "claves lectoriales» constitutivas de la cotidianeidad en la obra. Nos parece que su trabajo constituye la demostración de una intertextualidad, que se caracteriza en primer lugar por la búsqueda de los rasgos identificadores, para alcanzar finalmente los sintagmas textuales intertextualizados, capaces de transformar las simples señales en claves de lectura de la obra 4 .

De otro lado, Miguel Ángel Garrido Gallardo, a propósito de «Los zapatos de Concha Velasco»" ${ }^{5}$, trata de demostrar cómo es posible - a partir del artículo de F. Umbral titulado «Los antihéroes»- revestir de "poeticidad» (literariedad) lo meramente cotidiano. En nuestra cultura, se pueden trocar poéticas, comunicaciones cotidianas que institucionalmente no lo son de ningún modo; esto es, la figurativización puede instaurar como literaria o poética una realidad cotidiana.

Lorenzo Vilches, en relación con la semiótica de la imagen, ofrece una comunicación en la que problematiza acerca de las «Nuevas tecnologías de la imagen y el fin de lo teatral $»^{6}$. Tras reconocer algunas precisiones en $\mathrm{C}$. Metz y R. Barthes a propósito de los códigos de la imagen, L. Vilches desarrolla en la parte última de su comunicación una sustanciosa digresión crítica sobre algunas de las tareas para la semiótica. «Probablemente -dice-, la semiótica, especialmente la europea, deberá volver a ocuparse con fuerza del problema de los signos y el iconismo, por una parte, y de la filosofia del lenguaje, por otra, con el fin de tender un puente hacia la investigación de ese nuevo universo de lenguajes»" ${ }^{7} \mathrm{Si}$, como en efecto ase-

- Otras obras recientes del doctor Ángel Díaz Arenas son La instancia del autor/lector (1986) y Las perspectivas narrativas (1988), ambas en Kassel, Reichenberger.

"Vid. Garrido Gallardo, M. A., «Los zapatos de Concha Velasco (apostilla sobre tematización poética de lo cotidiano)", Actas del II Congreso Internacional de AES, Universidad de Oviedo, 1988, pp. 187-201.

6 Vid. Vilches, L., op. cit., 1988, pp. 439-451. A propósito de unas declaraciones que hizo a la prensa asturiana sobre el discurso televisivo, vid. Maestro, J. G., "Lorenzo Vilches: La televisión programa nuestra vida cotidiana», La Nueva España, Oviedo, 15 de marzo de 1987. También en relación con la semiótica visual, véase la entrevista con Didier Coste, con motivo de una conferencia pronunciada en Oviedo el 5 de diciembre de 1986 titulada "Semiótica y retórica audiovisual en los textos literarios» (vid. Maestro, J. G., "Didier Coste: No hay literatura en sí,-sino comunicación literaria», La Nueva España, Oviedo, 6 de diciembre de 1986).

'Vid. Vilches, L., op. cit., 1988, p. 448. 
guraba Peirce, la semiología se fundamenta en una teoría del conocimiento que se expresa en la relación entre representación cognoscitiva y objetividad conocida, los signos - dice Vilches- siempre tendrán una «conexión causal con objetos concretos», siendo el origen de proyecciones de transformación que posibilitan al hombre el conocimiento del mundo. El pensamiento no es, pues, sino la manipulación racional de tales signos e ideas.

\section{LO TEATRAL}

Marco di Marinis, profesor de la Universidad de Bolonia, en su sesión plenaria "Attraverso lo specchio. Per una ridefinizione dello spettacolo teatrale nei suoi rapporti con il quotidiano" of reció una síntesis y una definición del espectáculo teatral - tema iniciado por María del Carmen Bobes- en sus relaciones con lo cotidiano, tema tratado a su vez por el profesor H. Parret en su intervención inicial.

Para Marco di Marinis el teatro no es - no lo ha sido munca- solamente reproducción, reflejo ficticio de la vida, de lo real, de lo social..., acontecimiento o representación real, ni tan siquiera simulación o ficción representativa, en puridad.

Según sus palabras, es precisamente desde aquí, desde lo cotidiano - tema de este congreso-, desde donde es posible confeccionar una «ridefinizione" del hecho teatral, a partir de tentativas semiológicas relacionadas con lo cotidiano. Así, «l'obiettivo costante, seppur volta a volta diversamente intenso e perseguito, è quello di restituire al teatro la sua natura di evento vivente, caratterizzato - per dirla con Cage - dalla stessa imprevedibilità, complessità e ineterminatezza che è propria della vita, degli eventi naturali»" ${ }^{8}$.

Según F. Abad, todo género literario es una «realidad institucional e histórica» sometida a la formulación de normas compositivas o principios de conducta artística tales que posibilitan la expresión creativa. En sus plateamientos "Sobre el teatro como género dramático", Francisco Abad reitera una vez más: «El teatro es representación y no sólo texto pronunciado, y a su naturaleza compleja deberán responder las definiciones y caracterizaciones que de él se hagan ${ }^{9} \gg$. El propio J. Mukavrovsky dejó escrito (vid. Escritos de estética y semiótica del arte, Barcelona, Gustavo Gili, 1977, pp. 231-234) que el teatro se caracteriza precisamente por que se constituye

\footnotetext{
"Vid. Marinis, M. di, op. cit., 1988, t. I, pp. 9-40, p. cit. 19. cit. 45 .

"Vid. Abad, F., «Sobre el teatro como genero dramático", op. cit., 1988, pp. 41-57, p.
} 
de «elementos compositivos que no pueden reducirse sólo al texto dramático».

Manuel Sito Alba, al estudiar «La funcionalidad de la semiótica teatral» ${ }^{10}$, repasa el significado del étimo latino theatrum, y su precedente griego $\theta \varepsilon \alpha \tau \varrho o v$, vocablos estrechamente vinculados al significado «mirar», lo que determina en el teatro la funcionalidad de lo visual. Agradece el lector, una vez más, la iteración de los seis componentes esenciales del teatro: 1) autor y director de escena, 2) texto escrito y códigos complementarios, 3) actores y personajes, 4) espacio real y espacio representado, 5) tiempo real y tiempo representado y 6 ) público presente. $\mathrm{Si}$, como escribió Ortega y Gasset ${ }^{11}$, el teatro es metáfora visible, suponemos que habrá de serlo precisamente porque lectores y personajes están unidos en vivo y en directo; y es precisamente en la combinación simultánea de estos dos elementos en lo que se diferencia el teatro de la cinematografia, de la literatura escrita y de la representación circense.

Es indudable también que el texto dramático se constituye en un complejo proceso de comunicación teatral, que se inicia en el texto escrito y no culmina en la representación, sino al llegar al público, a ese espectador que es capaz de atender y entender la forma expresiva de una idea bella, lo cual supone tener suficientemente educados sus órganos sensoriales, su atención y su inteligencia imaginativa, para poder apreciar el pensamiento estético del autor y de su obra.

José Romera Castillo, en "Semiótica teatral en España», ofrece un actualizado repertorio bibliográfico de los estudios sobre semiología del teatro en el país de Cervantes, subrayando que «no existe hasta el momento ninguna revista española especializada en semiótica teatral». Desde un punto de vista bibliográfico, los estudios semiológicos de la obra dramática han adquirido un lugar tan propio como significativo, si bien, por el momento, la narratología ocupa el primer espacio y la poesía el último ${ }^{12}$.

En «Una recepción crítica ideologizada: la crítica teatral del diario madrileño $A B C$ durante la II República», José Antonio Pérez Bowie, a partir del pensamiento de Anne Ubersfeld - Todo texto teatral es la respuesta a una demanda previa -, nos ofrece una explicación acerca de cómo un discurso verbal puede constituirse en subconjunto de una formación ideológica capaz de determinar los procesos semánticos. Se trataría, en suma, de un

${ }^{10}$ Vid. Sito Alba, M., op. cit., 1988, pp. 425-436. Vid. también del mismo autor «El mimema, unidad primaria de la teatralidad», Actas del III Congreso de la Asociación Internacional de Hispanistas, Roma, Bulzoni, 1982, t. II, pp. 971-978. 36.

"Vid. Ortega y Gasset, J., Idea del teatro. Madrid, Revista de Occidente, 1958, pp. 34-

12 Vid. Romera Castillo, J., "Crítica semiótica de la poesía en España», VII Congreso de la Sociedad Española de Literatura General y Comparada, Barcelona, octubre de 1988. 
horizonte de expectativas mediatizado por criterios ideológicos y comprometidos, al margen de todo sistema de normas objetivadas.

Joaquina Canoa Galiana, en «La cotidianeidad en el teatro de Ionesco», estudia, a partir de los tres componentes de la dinámica teatral de Eugene Ionesco - personajes, objetos, lenguaje-, los motivos recurrentes de El Rinoceronte (1960) y La cantante calva (1950) como principios básicos de la comunicación humana, muy principalmente en el teatro.

Diremos, en definitiva, que la aportación documental y explicativa de las Actas del II Congreso Internacional, celebrado en Oviedo, nos aproximan a la semiótica concebida como una dimensión humana específica. Desde la primitiva identidad entre la filosofia y la teoria de los signos, tal como proponia Morris ${ }^{13}$, los estudios de semiologia han evolucionado -creemos - sana y saludablemente, hasta convertir en objeto propio de su estudio aquellas creaciones humanas que remiten a un significado.

Todo lo que hace el hombre significa, y todo cuanto significa es hoy objeto de la semiología. Sin embargo - lo decíamos al principio-, aquella frase que F. de Saussure estampó en su Course - «la semiología tendrá mucho que hacer sólo para ver hasta dónde alcanza su dominio»-, apenas hoy nos resulta problemática. Y es que la literatura - lo dijo Schellingsólo puede emerger mediante «el deslinde del discurso de la totalidad del lenguaje»" ${ }^{14}$ nuestra ciencia, afortunadamente, es tan sólo una ficción explicativa, la historia —creemos- especialmente ideología.

1. Vid. Morris, Ch., Ensayos sobre la filosofia del lenguaje, Madrid, 1973.

14 Vid. Schelling, Philosophie der Kunst, Darsustadt, 1960, p. 279. 